PAPERS IN PHYSICAL OCEANOGRAPHY AND METEOROLOGY

Published by

MASSACHUSETTS INSTITUTE OF TECHNOLOGY

AND

WOODS HOLE OCEANOGRAPHIC INSTITUTION

VOL. IX, NO. 2

\title{
THE PROGESSES DETERMINING THE CONCEN- TRATION OF OXYGEN, PHOSPHATE AND OTHER ORGANIC DERIVATIVES WITHIN THE DEPTHS OF THE ATLANTIC OCEAN
}

\author{
BY \\ ALFRED C. REDFIELD \\ Woods Hole Oceanographic Institution \\ and \\ The Biological Laboratories \\ Harvard University
}

Contribution No. 308 from the Woods Hole Oceanographic Institution

CAMBRIDGE AND WOODS HOLE, MASSACHUSETTS

September, $194^{2}$ 
, 


\section{CONTENTS}

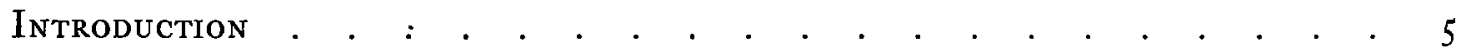

The Distribution of Total Inorganic Phosphate . . . . . . . . . . . 6

The Distribution of Apparent Oxygen Utilization . . . . . . . . . 7

The Relation of Phosphate and Oxygen. . . . . . . . . . . . . . 7

The Distribution of Preformed Phosphate. . . . . . . . . . . . . 10

The Horizontal Transport of Phosphate Derived from Oxidative Decom-

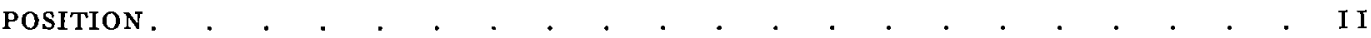

The Phosphate Derived from the Surface of the Temperate and Tropical

$\operatorname{OCEAN}$. . . . . . . . . . . . . . . . . . . . . .

The Origin of the Phos phate in the Subsurface Layers of the Warm Oceanic Basins . . . . . . . . . . . . . . . . . . . . . I5

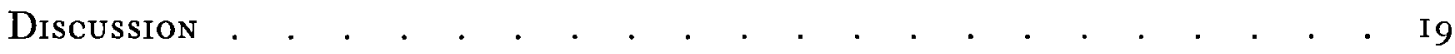

Summary . . . . . . . . . . . . . . . . . . . . . . $2 \mathrm{I}$

References . . . . . . . . . . . . . . . . . . . . . $2 \mathrm{I}$ 


\section{INTRODUCTION}

The great oceans of the world all contain at intermediate depths less oxygen and more nitrate and phosphate than is found at either lesser or greater depths. This is one of the most marked physical features of the sea which must be attributed to the action of biological agencies.

Those who have discussed this condition recently are agreed that it originates through the oxidation of organic matter derived primarily from the surface layers of the ocean, where alone the original synthesis of organic matter can occur. The condition obtaining at any depth is considered to depend upon the balance between the rate at which oxygen is removed from the water by respiratory and other metabolic processes and the renewal of oxygen in the layers in question by movements of the water. One group of investigators has emphasized the latter factor as the dominant one in determining the observed distribution of oxygen (Jacobsen, I916; Dietrich, 1937; Wüst, I935; Wattenberg, I929, 1938). Oxygen content is reduced to the greatest extent at those depths in which the water is in minimal motion and hence the renewal of oxygen is least. Seiwell (1937) and Sverdrup (1938) have pointed out that this condition is not a necessity and is indeed in certain situations contrary to the apparent facts. They have shown that the observed distribution of oxygen may be accounted for by assuming various suitable relations between the rates at which oxidation occurs as a function of the depth and the rates of renewal by the circulation of water.

These discussions appear to consider the state of the water to depend upon factors operative more or less locally and in situ. Specifically, oxidation is assumed to follow the sinking of organic matter from the surface to the depth in question in the discussions of Wattenberg (1937) and Seiwell (1937). The renewal of oxygen is assumed to depend on the horizontal circulation.

Several considerations appear to have been given insufficient weight in discussions of this subject. It is not at all clear why the depth of the oxygen minimum layer varies so greatly from place to place or what its relation is to the particular nutritive conditions in the sea's surface. Observations made in the relatively shallow water of the Gulf of Maine indicate that organic decomposition and oxidation take place for the most part not far from the sea surface. It seems not unreasonable to assume that the properties of the water which depend upon organic decomposition may have been determined primarily at a time when the water was relatively near the sea surface and that the water has subsequently moved into its observed position. The recent evidence, reviewed by Montgomery (1940), that mixing processes along surfaces of constant potential density may occur with great ease, even in the absence of directional flow, provides a convenient mechanism for establishing a distribution of oxygen and the products of organic activity at great depths which is dependent in large part on processes taking place much nearer the sea surface in remote regions. These considerations have suggested that the wellmarked evidence of decomposition which is observed at great depths in the central Atlantic Ocean may be due to the flow of water along surfaces of equal potential density from regions near the sea surface in high northern and southern latitudes rather than to: the decay of organic matter derived directly from the overlying surface waters.

This view requires that the characteristics of the water show a marked continuity in their distribution along layers of constant potential density, and that these layers emerge 
at or near to the sea surface in places suitable to produce the peculiar character of the layers in question.

To test this possibility, data secured by the "Meteor," the "Discovery," and the "Atlantis" have been examined. The most illuminating information was secured from two north-south sections which together extend from Greenland to Antarctica. The South Atlantic was traversed by a section, made by the "Discovery" in April-May, I93I, extending along the thirtieth meridian from $57^{\circ} 36^{\prime} \mathrm{S}$ to $14^{\circ} 27^{\prime} \mathrm{N}$ ("Discovery" Reports, I 932). This is Section 2 of Clowes (1938). A section of the North Atlantic was constructed from the data secured by the "Atlantis" extending from $\mathrm{I}^{\circ} \mathrm{N}$ to $34^{\circ} \mathrm{N}$ west of the fortieth meridian in March, I932 (Stations I I 58-I I79), and from $39^{\circ} \mathrm{N}$ to $49^{\circ} \mathrm{N}$ near the fortieth meridian in September, I935 (Stations 2485-249I), and by the "Meteor" (Stations I 20-I25) extending from $50^{\circ} \mathrm{N}$ to $58^{\circ} \mathrm{N}$ near the forty-fourth meridian, occupied in March, I935 (Bull. Hydrographique, 1933, 1936).

The data have been converted in to suitable common units. Phosphate has been expressed as milligram-a toms phosphorus per cubic meter ( $\gamma$-a toms $P$ per liter) uncorrected for salt error. The function of the oxygen content which is of importance is the quantity which has disappeared from the water owing to metabolic processes. This has been approximated by assuming the water to have been saturated with air at the time it acquired its temperature and salinity at the sea surface and subtracting the recorded oxygen content from the value calculated on this assumption. The "apparent oxygen utilization" so obtained has been expressed as cubic centimeters per liter.

In plotting the data for the sections, a rectangular grid on which latitude is represented horizontally and sigma- $t$ is represented vertically has been chosen. Montgomery (I938) has shown that surfaces of equal sigma-t are approximately of constant potential density. Consequently, on such a diagram the path of free movement by lateral mixing or flow is along horizontal lines. Any correlation of the distribution of a component of the sea water with potential density becomes at once apparent, if present. The surface of the sea and surfaces of any particular depth are represented by curved lines on the diagram. A grid of this type has been used by Spilhaus (I94I) to distinguish different water types in the complex situation which exists at the margin of the Gulf Stream.

\section{THE DISTRIBUTION OF TOTAL INORGANIC PHOSPHATE}

Figures $I$ and 3 represent the distribution of total inorganic phosphate in the sections. The concentration of phosphorus is clearly correlated in a general way with the distribution of potential density. The phosphorus isopleths extend horizontally from $50^{\circ} \mathrm{N}$ to $50^{\circ} \mathrm{S}$ with maximal concentrations lying in water of density characterized by $\sigma_{\iota}$ lying between 27.2 and 27.8. These layers emerge at the sea surface north of $50^{\circ} \mathrm{N}$ and cut the $200-m e t e r$ isobath in the neighborhood of $50^{\circ} \mathrm{S}$. The more generalized features of phosphate distribution are consequently compatible with the view that this substance may have originated by decomposition in waters near the sea surface in high laitudes and have spread from there to the greater depths of the ocean basin by lateral mixing or by isentropic flow.

The distribution of phosphate shows, however, one feature which precludes such processes as being the sole important source of the phosphorus of the deep oceanic water. In the low latitudes $\left(10^{\circ} \mathrm{S}\right.$ to $20^{\circ} \mathrm{N}$ ) the concentration of phosphate, in water of any given potential density, is higher than in similar water lying to the north or south. Bands of water relatively poor in phosphate separate the equatorial water masses from the layers 
of high phosphate content which emerge near the sea surface in high latitudes. The movement of water along surfaces of equal potential density cannot account for the increase in phosphate content which appears in the equatorial region. In this region the maximal concentrations. occur in waters of slightly lower potential density $\left(\sigma_{t}=27.2-27.4\right)$ than is the case in high latitudes $\left(\sigma_{t}=27.4-27.6\right)$.

A careful examination of the "Meteor" data for phosphate in the South Atlantic appears to preclude the possibility that the high phosphorus content of the water in tropical regions is derived from the antarctic region by movement in paths not cut by the section.

Some process acting locally in the equatorial region must supplement the assumed transport of phosphate from the polar regions along surfaces of constant potential density. The problem is to separate and evaluate these two aspects of phosphate distribution. For this purpose a comparison of the occurrence of oxygen and phosphate is helpful.

\section{THE DISTRIBUTION OF APPARENT OXYGEN UTILIZATION}

Figures 2 and 4 represent the quantities of oxygen which appear to have been removed from the water of the sections since it was saturated at the surface. In the North Atlantic section the apparent oxygen utilization parallels closely the concentration of phosphate shown in Figures $I$ and 3 and is correlated with the potential density of the water layers, as Seiwell (1937) has pointed out. Maximal losses in oxygen occur in water of sigma- $t$ between 27.2 and $27.4 .^{1}$ In the South Atlantic, on the other hand, the apparent loss in oxygen coincides with the phosphate content in its distribution relative to sigma- $t$ only south of $35^{\circ} \mathrm{S}$ latitude. In the equatorial region the loss in oxygen is much more pronounced than is the gain in phosphate, particularly in waters lighter than $\sigma_{t}=27.4$. Waters of the same potential density have lost very different quantities of oxygen in different latitudes. The apparent utilization of oxygen reflects in an exaggerated way the action of those processes which seem to increase the phosphate in the deep waters of the ocean in low latitudes.

\section{THE RELATION OF PHOSPHATE AND OXYGEN}

In a discussion of the organic derivatives of oceanic water (Redfield, I934), it has been pointed out that the deeper waters of the North Atlantic contain more nitrate and phosphate than can be accounted for by the quantities of oxygen which have disappeared in the oxidation of organic matter. It was suggested that these extra concentrations of nutrient salts were already present as such in the water when it sank in high latitudes. Reference to Figures I and 3 will show that at latitudes higher than $50^{\circ} \mathrm{N}$ and $45^{\circ} \mathrm{S}$ the surface waters contain nearly half as much phosphate as does the richest water in any part of the sections. The sinking and subsequent isentropic movement of such water would carry in to the oceanic depths large quantities of phosphate which is entirely independent in origin of processes of organic decomposition and oxidation taking place after the water left the sea surface. Such phosphate will be called preformed phosphate hereafter.

By making use of the ratio between the utilization of oxygen and the appearance of phosphate observed in the more superficial oceanic water in which preformed phosphate is absent which agrees closely with the ratio to be expected from the average composition

\footnotetext{
1 These are slightly higher values of sigma-t than Seiwell found to characterize the water of minimal oxygen content $\left(\sigma_{\ell}=27.23\right)$. In a column of oceanic water the layer of minimal oxygen content may be expected to lie somewhat above the layer of maximum oxygen utilization since the lighter water, being warmer, does not contain as much oxygen when saturated. A given oxygen utilization will consequently reduce the oxygen content of the lighter water to a lower value
than in the case of the heavier water which lies below.
} 


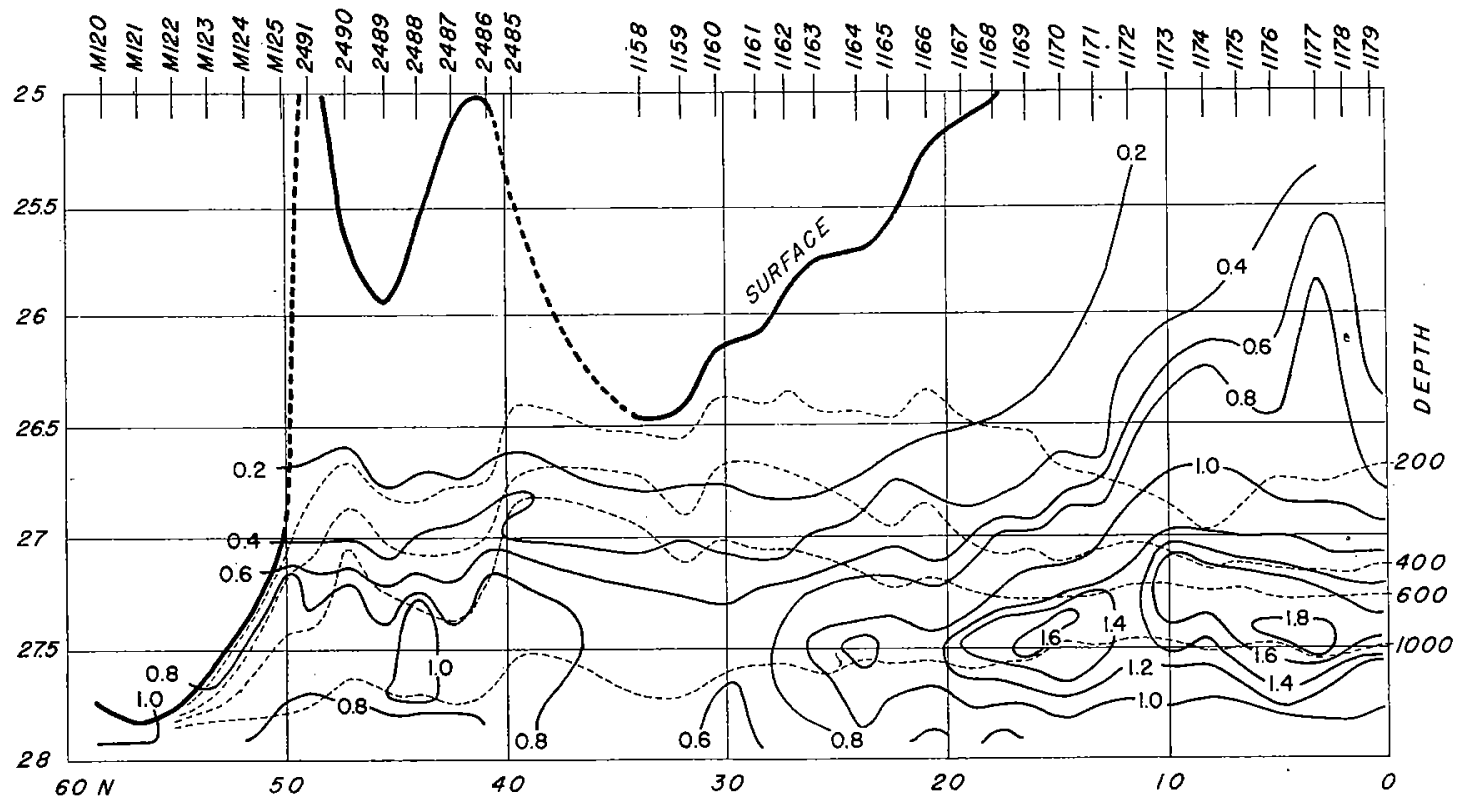

FIG. I. Distribution of total inorganic phosphate in North Atlantic section. Ordinate; sigma-t. Abscissa; latitude. Solid contours; total inorganic phosphate (mg. atoms of phosphorus per cubic meter). Broken contours; depth (meters).

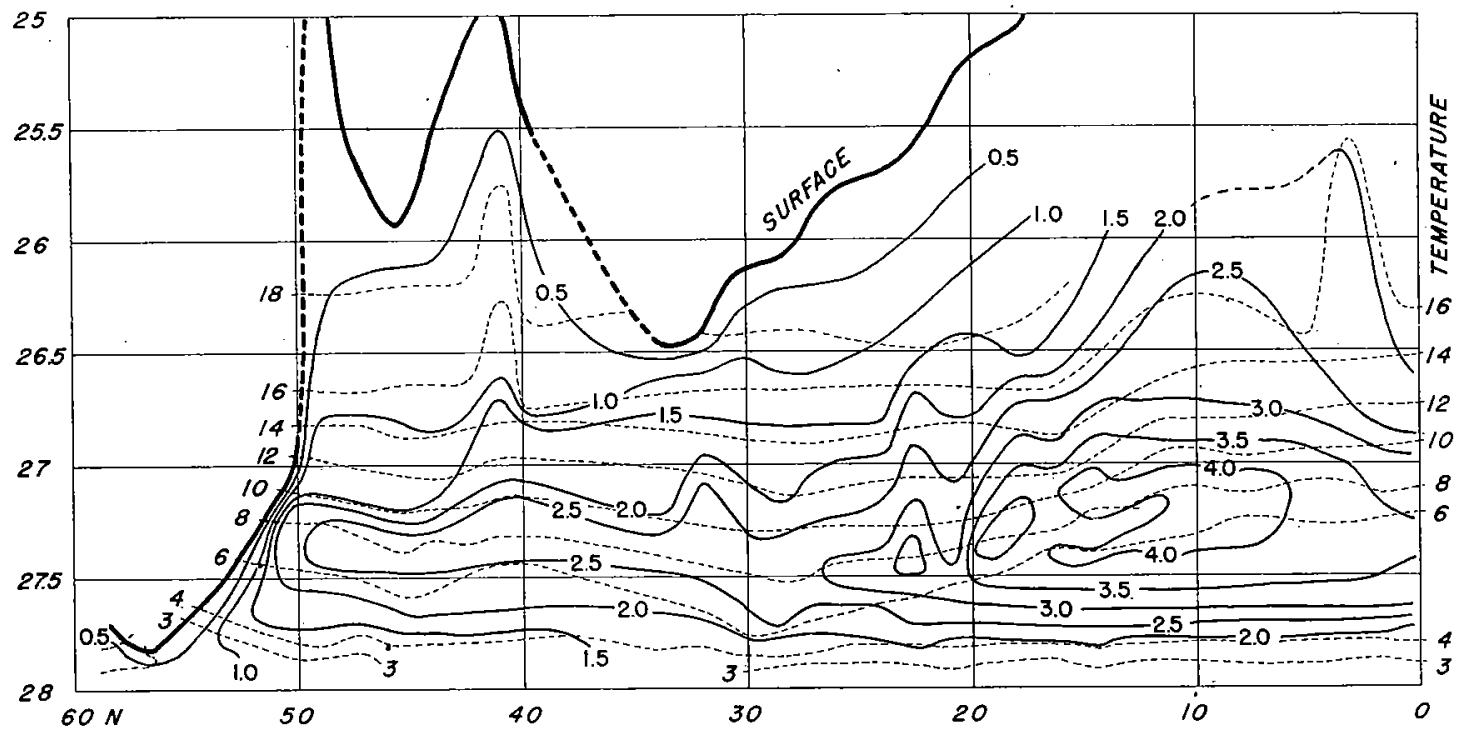

FIg. 2. Distribution of apparent oxygen utilization in North Atlantic section. Ordinate; sigma-t. Abscissa; latitude. Solid contours; apparent oxygen utilization (cc. per liter). Broken contours; temperature $\left({ }^{\circ} \mathrm{C}\right)$. 


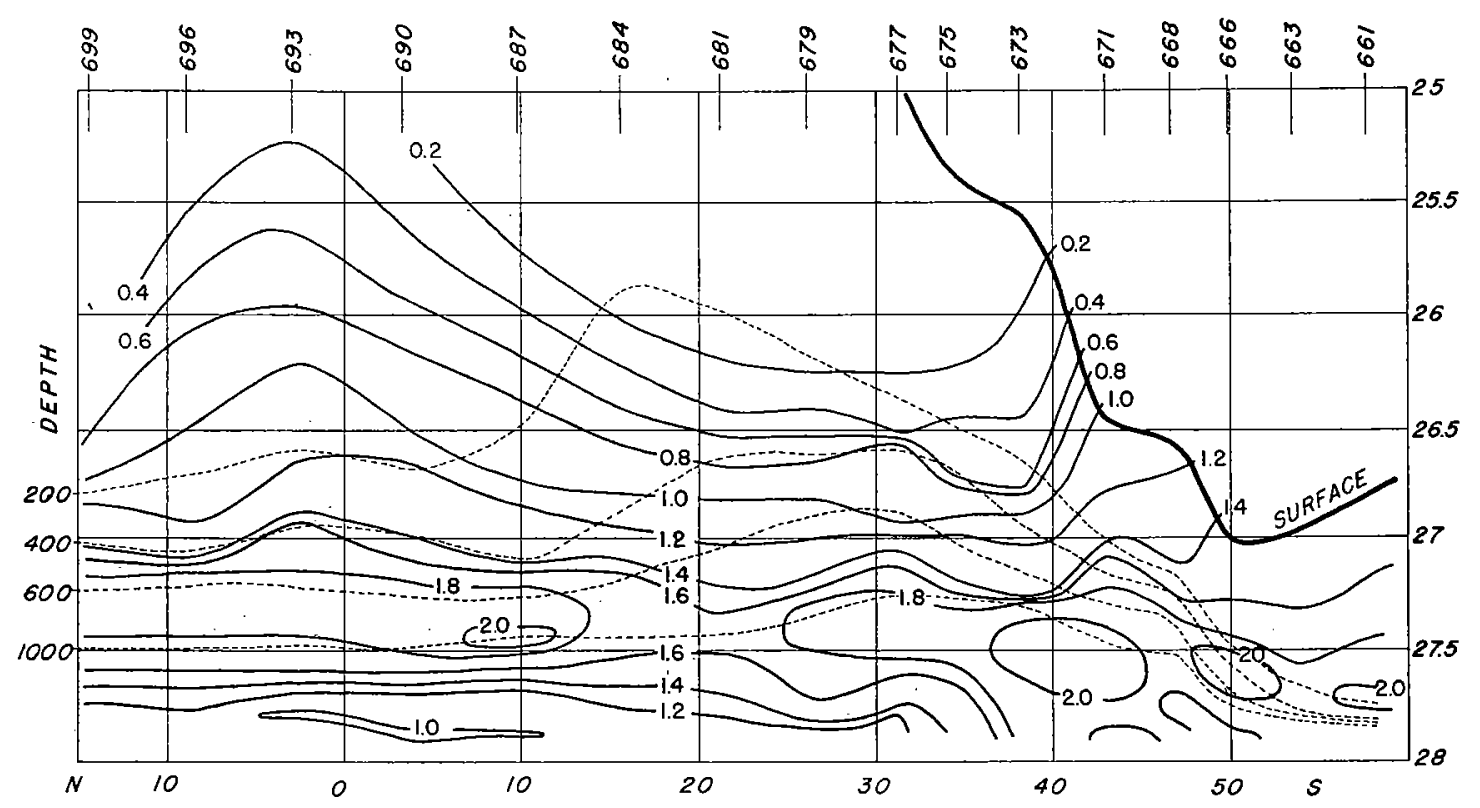

FIG. 3. Distribution of total inorganic phosphate in South Atlantic section. For explanation, see legend Fig. I.

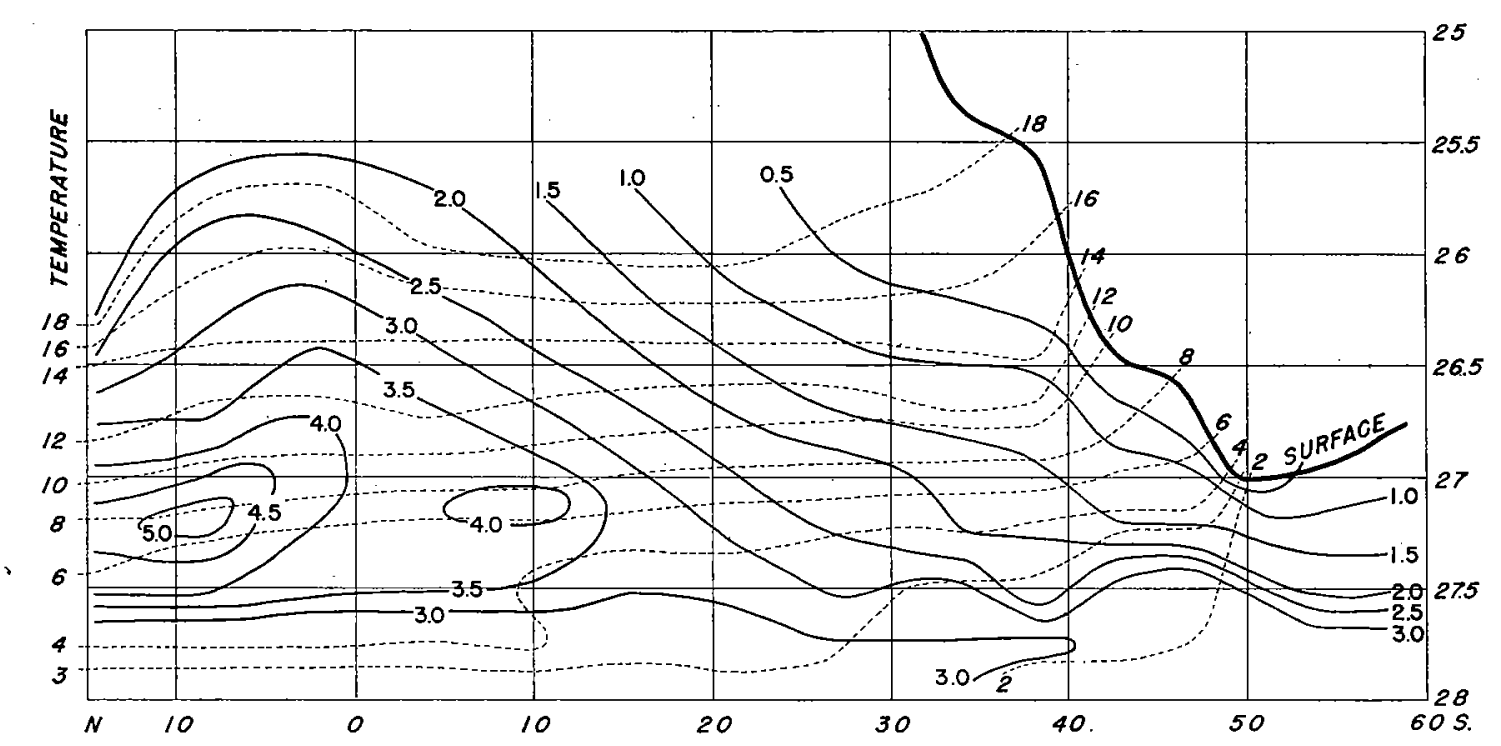

Frc. 4. Distribution of apparent oxygen utilization in South Atlantic section. For explanation, see legend Fig. 2. 


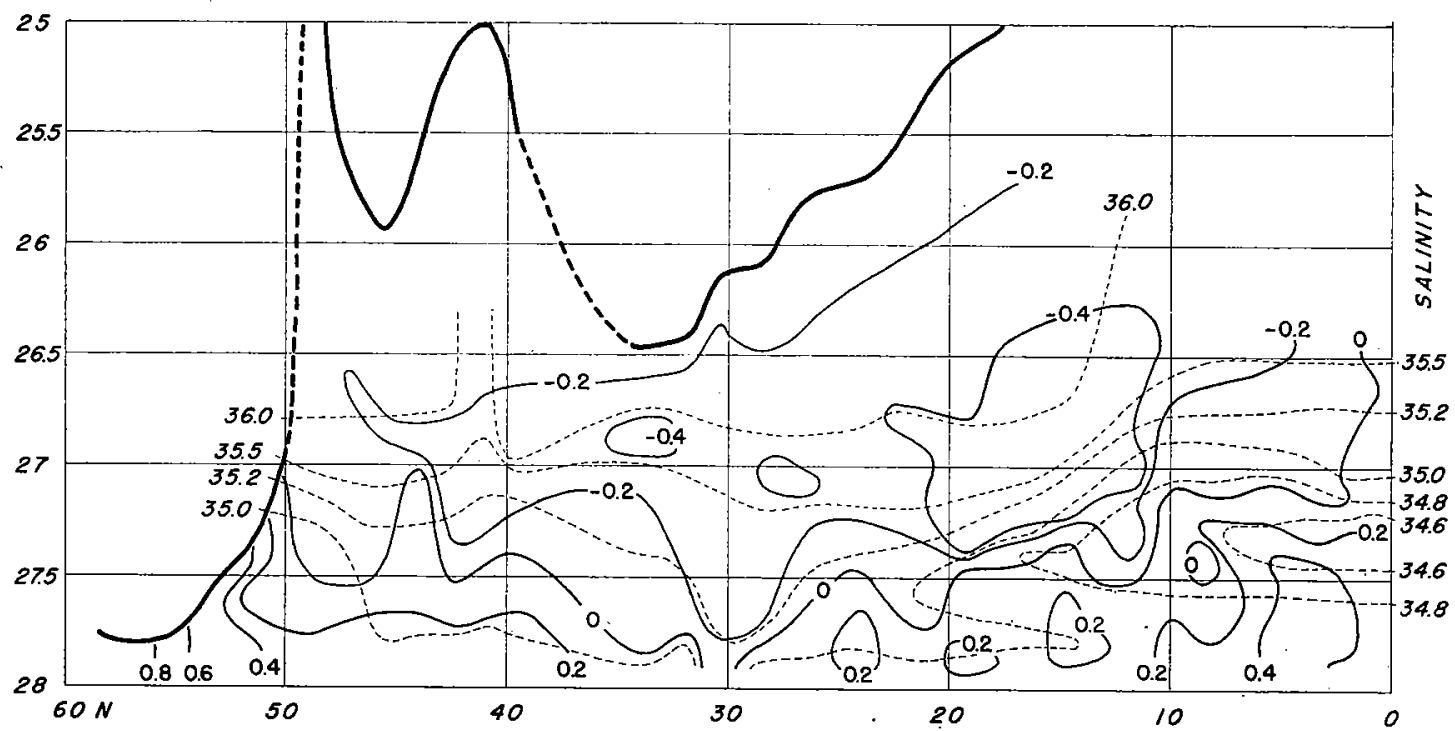

Fig. 5. Distribution of preformed phosphate in North Atlantic section. Ordinate; sigma-t. Abscissa; latitude. Solid contours; preformed phosphate (mg. atoms of phosphorus per cubic meter). Broken contours; salinity (\% $\%$ ).

of marine plankton (Redfield, I934; Cooper, I937; Fleming, I94I), it is possible to make a rough estimate of the quantity of phosphate liberated in each part of the sections by those processes of decomposition which are accompanied by the utilization of oxygen. The difference between these quantities and the total quantities of phosphate found in the water represents the quantities of preformed phosphate. The importance of estimating the distribution of this fraction lies in the fact that it can have obtained its distribution only as the result of water movements.

To carry out this estimate, it has been assumed that the disappearance of I cc. of oxygen is accompanied by the appearance of $0.373 \times 10^{-3}$ milligram a toms of phosphorus. ${ }^{2}$ This equivalence is based on the observation, made in the waters of the Sargasso Sea above 1,000 meters, that the disappearance of 6 millimols of oxygen accompanies the appearance of I millimol of nitrate and I/20 millimol of phosphate (Redfield, 1934). The data for the apparent oxygen utilization in cc. per liter have been multiplied by 0.373 to obtain the fractions of the phosphate in milligram atoms $\mathrm{P}$ per cubic meter which have appeared in the water following oxidative decomposition since the water was saturated at the surface. The difference between these fractions and the total represents the fractions which have been designated preformed phosphate.

\section{THE DISTRIBUTION OF PREFORMED PHOSPHATE}

Figures 5 and 6 show the distribution of the preformed phosphate as estimated in this way. In the South Atlantic (Figure 6) the preformed phosphate appears as a definite tongue originating in high concentration in water of $\sigma_{\iota}=27.2$ to 27.6 which underlies the antarctic convergence in $45^{\circ}$ to $50^{\circ} \mathrm{S}$ latitude. The tongue extends northward at these potential densities to at least $15^{\circ} \mathrm{N}$ latitude, its concentration meanwhile becoming progressively attenuated.

2 This equivalence is slightly greater than that proposed by Fleming (194I), who on the basis of various analyses of plankton suggests I ml. $\mathrm{O}_{2}=0.013 \mathrm{mg}$. $\mathrm{P}$ ( $\mathrm{I}$ cc. $\mathrm{O}_{2}=0.334 \times 1 \mathrm{O}^{-3} \mathrm{mg}$. atoms $\mathrm{P}$ ). I have preferred to use a figure based directly on sea water analyses. 


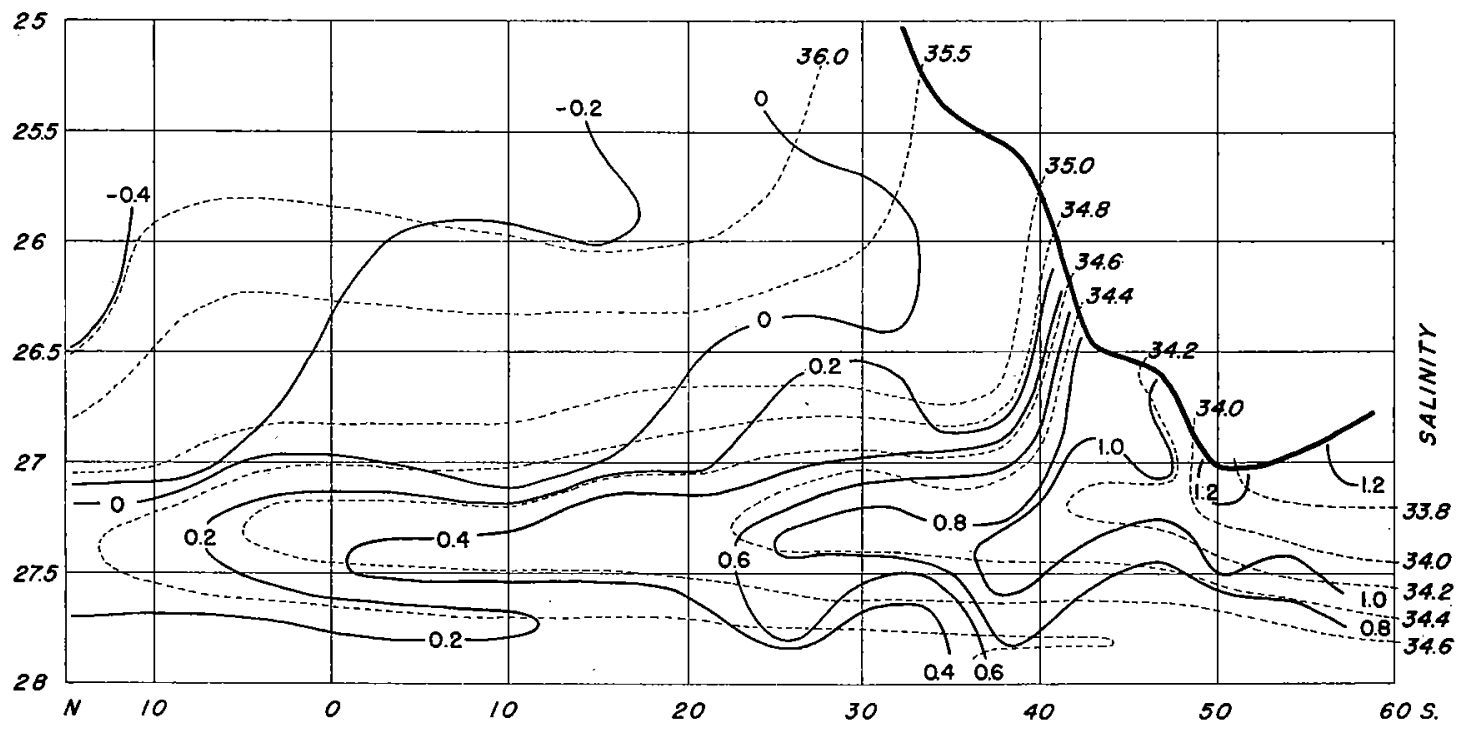

FIG. 6. Distribution of preformed phosphate in South Atlantic section. For explanation, see legend Fig. 5.

On the same diagram the salinities of the water are also represented. The tongue of water of relatively low salinity, the sub-antarctic intermediate water of Wüst, corresponds closely with the distribution of preformed phosphate and evidently becomes attenuated at very much the same rate by mixing with other masses of water. The closeness of this correspondence between salinity characteristics, which can only have arisen near the sea surface, and the distribution of preformed phosphate which has been assumed to have a similar origin, gives some confidence in the adequacy of the method by which the preformed phosphate has been estimated, and to the conclusion that this considerable fraction of the phosphate of deep oceanic water has been transported to the depths where it is found as the result of water movements along surfaces of equal potential density. ${ }^{3}$

In the North Atlantic the preformed phosphate does not constitute an important part of the total phosphate, except in the water underlying the most northern stations and in the extension of the antarctic intermediate water which intrudes from the South Atlantic (Figure 5). It takes no important part in developing the phosphate maximum of this region. It is present, however, in small quantities in water of density greater than $\sigma_{t}=27.7$ and in its distribution is associated with water of less than $35 \%$ salinity, the middle North Atlantic deep water of Wüst.

\section{THE HORIZONTAL TRANSPORT OF PHOSPHATE DERIVED FROM OXIDATIVE DECOMPOSITION}

The preformed phosphate, which appears to intrude into the depths of the South Atlantic with the movement of the subantarctic intermediate water, represents only a part of the phosphate present in that water when it leaves the region of the antarctic convergence. Thus water at "Discovery" station $67 \mathrm{I}$, latitude $43^{\circ} \mathrm{S}$, depth 600 meters,

\footnotetext{
${ }^{3}$ Clowes (1938) recognizes that the antarctic intermediate water contains a high phosphate content derived from both plankton and phosphate present in the antarctic surface water. He notes that a falling off in phosphate content of this water as it moves toward the north is to be expected as mixing at the upper and lower boundaries takes place. He states that this falling off is not found. However, he does not distinguish between the origins of the various phosphate fractions observed in the section. Onlv when this is done does the attenuation of phosphate of antarctic origin become apparent.
} 
$\sigma_{i}=27.2$, contained $\mathrm{I} .90 \times 10^{-3}$ milligram atoms $\mathrm{P}$ per liter. Of this only $0.90 \times 10^{-3}$ milligram atoms is attributed to preformed phosphate. The remainder may be accounted for by processes which have removed oxygen from the water-that is, by the decomposition of organic matter of local origin since the water left the surface. Water movements which carry the preformed phosphate northward will also transport the phosphate derived from oxidative decomposition northward and will at the same time account for a corresponding deficiency of oxygen along the course of this water movement. A part of the oxygen minimum and phosphate maximum of the South Atlantic consequently may be derived from decomposition processes which have taken place far to the south.

The preformed phosphate and the phosphate derived from oxidative decomposition of

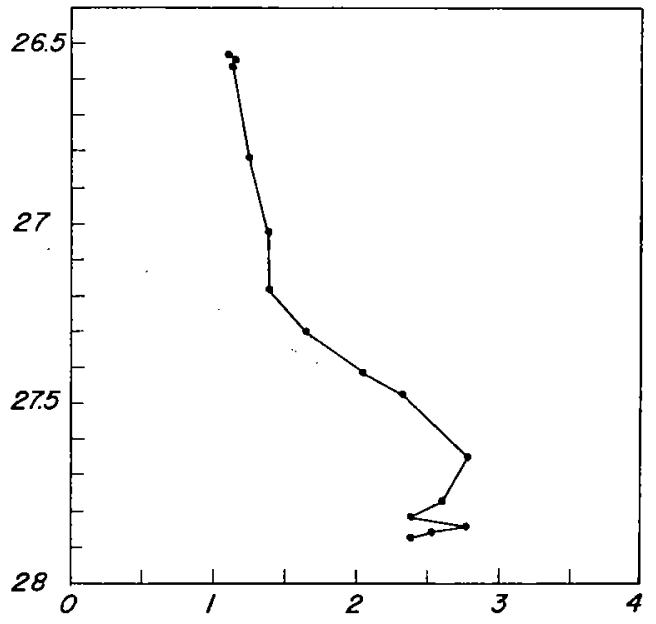

FIG. 7. Ratio of total phosphate to preformed phosphate in waters of various potential density at "Discovery" Station 67I ( $\left.43^{\circ} \circ 8^{\prime} \mathrm{S}, 30^{\circ} \times 5^{\prime} \mathrm{N}\right)$. Ordinate; sigma-t. Abscissa; ratio of total $\mathrm{P}$ to preformed $\mathbf{P}$. organic matter in the subantarctic intermediate water must be transported northward by the same mechanism and become attenuated by the same mixing processes as its transport proceeds. The total phosphate of southern origin occurring at any point may be calculated from the preformed phosphate found there if it is assumed that the water movement is solely along layers of constant potential density and that the attenuation is due to the mixing of water of southern origin with other water having the same potential density but containing no preformed phosphate.

Under these conditions the total phosphate of southern origin will bear the same ratio to the preformed phosphate at any point as it did when the water first acquired its properties in the region of the antarctic convergence.

In order to determine how much of the phosphate present at any location in the section may be attributed to water moving along surfaces of equal potential density from the region of the antarctic convergence, the ratio of total phosphate to preformed phosphate has been determined for each value of sigma- $t$ at Station 671 (Figure 7). These ratios provide factors by which the preformed phosphate estimated to occur at any point may be multiplied in order to arrive at the total phosphate carried to that point by the water movements responsible for the presence of the preformed phosphate. Station $67 \mathrm{r}$ has been selected as a basis for these estimations since it yields rather lower values for the factor than those stations lying immediately north or south of it. The values obtained are consequently minimal and hence may lead to an underestimate of the contribution of the phosphate of southern origin to that found at great depths at lower latitudes. ${ }^{4}$

The general distribution of the phosphate fraction estimated to be derived from. oxidative decomposition in the neighborhood of the antarctic convergence and transported northward does not differ markedly from that of the preformed phosphate and

\footnotetext{
${ }^{4}$ This procedure cannot be very exact since it involves errors both in the estimation of preformed phosphate and in the determination of the proper factor. Moreover, the assumption that mixing is strictly along surfaces of equal potential density probably cannot be justified. The fact that the value of the total phosphate maximum is less in the neighborhood of $20^{\circ} \mathrm{S}$ latitude (see Fig. 3) than either north or south suggests that vertical mixing or some other water movement contributes to the attenuation of the preformed phosphate in its northward movement.
} 
consequently has not been separa tely illustrated. The magnitude of this fraction at various stations along the section is shown in Figure 9, which will be discussed below.

\section{THE PHOSPHATE DERIVED FROM THE SURFACE OF THE TEMPERATE AND TROPICAL OCEAN}

The procedures described above allow one to estimate the quantity of phosphate and the deficiency of oxygen which may have been derived by water movement from the

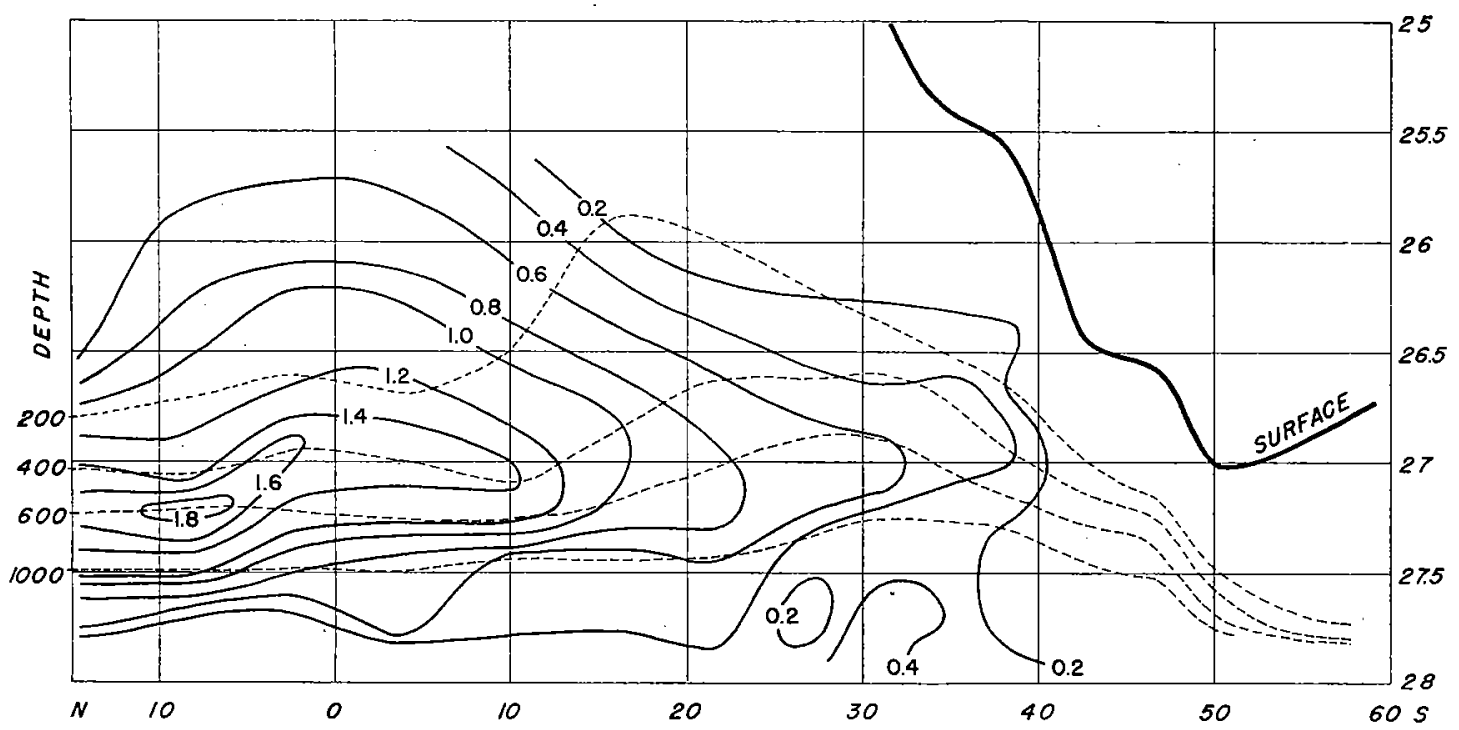

FIG. 8. Distribution of phosphate attributable to local oxidation in the tropical and temperate South Atlantic. Ordinate; sigma-t. Abscissa; latitude. Solid contours; phosphate of local oxidative origin (mg. atoms of phosphorus per cubic meter). Broken contours; depth (meters).

antarctic margin of the Atlantic Ocean. The remainder observed at any point must be attributed to the decomposition of organic matter derived more or less directly from the surface layers of the tropical and temperate ocean, either through the local sinking of organisms or movement of water.

Figure 8 represents the distribution of phosphate which must be attributed to local processes originating in the tropical and temperate regions of the South Atlantic section. The data have been obtained by subtracting the quantities of preformed phosphate and of the phosphate of oxidative origin which moves with it from the antarctic from the total phosphate found at each position. It shows that this material accumulates in greatest quantity at depths of 400 to 600 meters just north of the equator $\left(\sigma_{t}=27 . I-27.3\right)$, that it diminishes southward, and decreases rapidly at depths below 600 or 700 meters. ${ }^{5}$

${ }^{5}$ It has been suggested by one of the readers of this paper that the magnitude of the processes of decomposition of organic matter derived from the tropical and temperate parts of the ocean can be derived more directly from the information illustrated in Fig. 4 showing the distribution of apparent oxygen utilization in the South Atlantic section. Assuming strictly isentropic movement, it is evident that the apparent oxygen utilization increases as one proceeds northward along surfaces of constant potential density. If one takes the conditions existing at say $45^{\circ} \mathrm{S}$ to represent the original condition of the northward moving water, a diagram essentially similar to Fig. 8 may be constructed showing the additional oxygen utilization observed at any point. The magnitude of the changes attributable to local oxidation is, however smaller. The maximum additional oxygen utilization estimated in this way amounts to about $3.5 \mathrm{cc}$. oxygen per liter (equivalent to I. $3 \mathrm{mg}$. atoms phosphorus per cubic meter). The difference is due to the fact that this method of estimation neglects the demonstrable attenuation of the components (preformed phosphate) of the subantarctic intermediate water in its northward course. 
The relative contribution of the three fractions in to which phosphate has been divided to the total phosphate content of different parts of the section are illustrated in the station profiles shown in Figure 9. The right-hand curve, $T$, encloses the total phosphate ob-
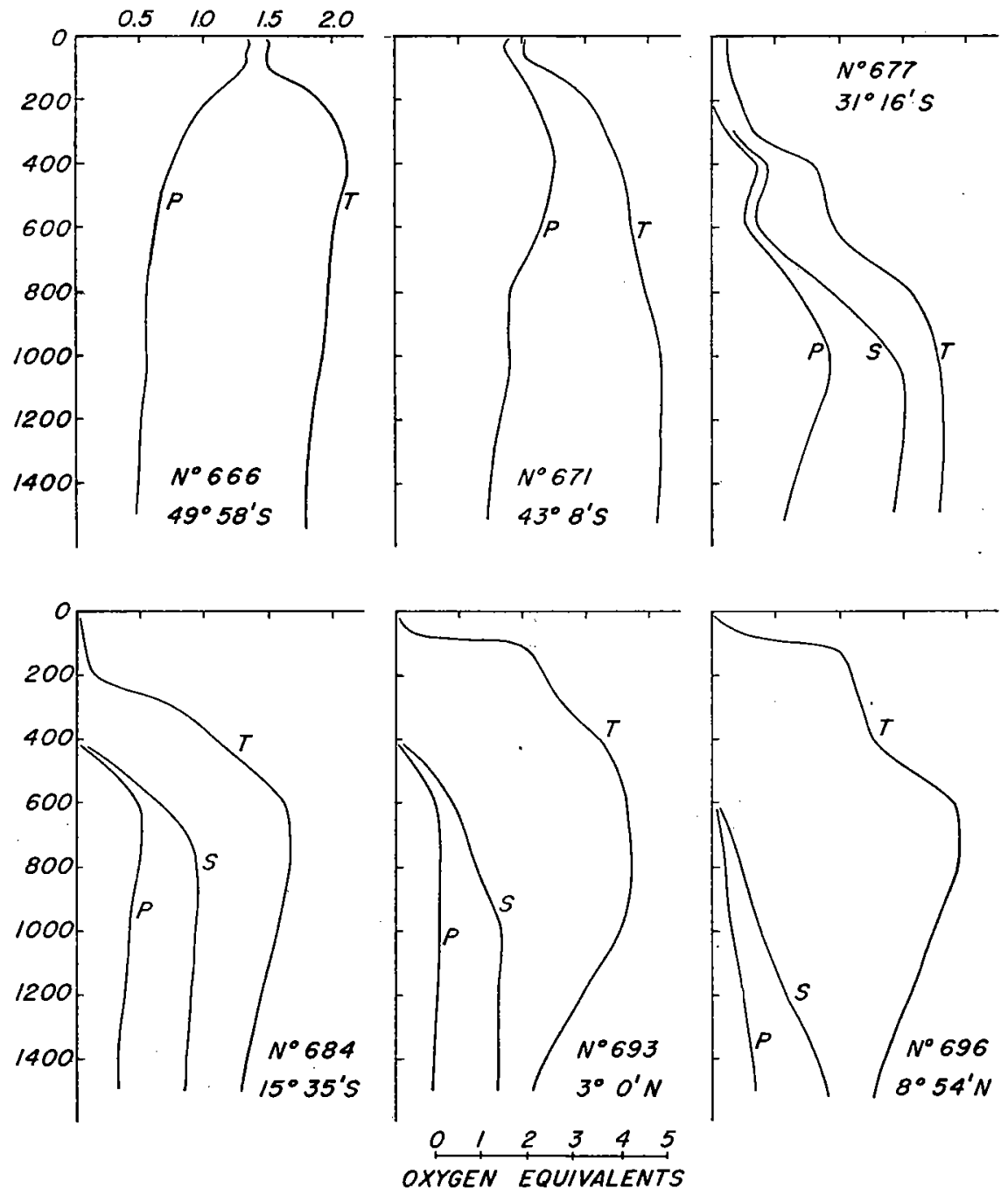

FIG. 9. Station profiles showing the distribution of phosphate attributed to various origins along the South Atlantic section. Ordinate; depth (meters). Abscissa; phosphate concentration (mg. atoms $\mathrm{P}$ per cubic meter). Curve $T$ represents total phosphate; curve $P$ represents preformed phosphate; curve $S$ represents preformed phosphate and phosphate of oxidative origin derived by isentropic movement from the region of the antarctic convergence. The scale of oxygen equivalents represents the corresponding oxygen utilization in cc. per liter.

served at the station. The left-hand curve, $P$, encloses the preformed phosphate. The intermediate curve, $S$, encloses phosphate estimated to have originated in the southern part of the section (preformed plus the phosphate of oxidative origin which moves with it). The spaces between the curves represent, reading from left to right, respectively the quantities of preformed phosphate, the recently formed phosphate of southern origin, 
and that of local origin. The latter two fractions are derived from estimates of the apparent oxygen utilization. The areas representing their distribution are proportional to the oxygen deficit which may be attributed respectively to remote and to local oxidative decomposition.

The profiles in Figure 9 show that as one passes northward the relative amount of phosphate of southern origin diminishes and is replaced by phosphate which cannot be derived from this source by lateral transport. The latter appears chiefly in the upper part of the water column, and at greater depths an increasing fraction of the total phosphate or oxygen deficit is to be attributed to the water which intrudes from the south.

In the North Atlantic section, the absence of preformed phosphate in water of density less than $\sigma_{\iota}=27.7$ indicates that the entire phosphate of the layers characterized by minimum oxygen and maximum phosphate is of recent oxidative origin. Whether these characteristics are attributable to isentropic transfers from near the surface or to the sinking and decomposition of organisms at greater depths is a question for discussion.

In the deeper layers, of density greater than $\sigma_{t}=27.7$, the properties of the water may be derived in large part from the lateral transport of water which has sunk in the far north, carrying with it preformed phosphate. Since this water contains less phosphate and a smaller oxygen deficit than the overlying layers in which these properties are maximally developed, it cannot have contributed to the development of these maxima, though vertical mixing with this deeper water may have led to the attenuation of these maxima. No attempt has been made to evaluate the relative importance of the origins of phosphate and oxygen deficit in these deeper layers, or to estimate their contribution to the layers above.

\section{THE ORIGIN OF THE PHOSPHATE IN THE SUBSURFACE LAYERS OF THE WARM OCEANIC BASINS}

Finally, we may inquire in to the origin of the phosphate in the waters lying at middle depths between the surface and the zone of maximal phosphate concentration in the oceanic basins. Must this be attributed to the decomposition of organisms which have sunk locally from the surface, or is it derived from isentropic movements of water from the subsurface layers of higher latitudes?

Iselin (1939) has recently shown that the characteristic temperature-salinity correlations displayed in the thermocline of the North Atlantic as one descends in depth are also observed in the surface waters of a north-south section. He has argued that these characteristics of the water encountered in a vertical sounding may have arisen from the movement of the successive layers from remote regions of the surface where the conservative properties were acquired, rather than being the result of vertical mixing processes as has been frequently assumed heretofore. We have applied a somewhat similar argument in seeking the source of the phosphate in these layers.

The temperature of the water in the regions in question can have been established only when the water was at the sea surface. If the phosphate concentration is also determined predominantly at or immediately below the surface, then in deeper waters phosphate concentration will behave essentially as a conservative property. On the view of the origin of the intermediate layer by isen tropic movement from the sea surface of higher latitudes proposed by Iselin, the temperature-phosphate correlations observed at any depth underlying a given station should be found in the subsurface waters of other stations and will be exhibited by all stations reached by the supposed isentropic movement. 


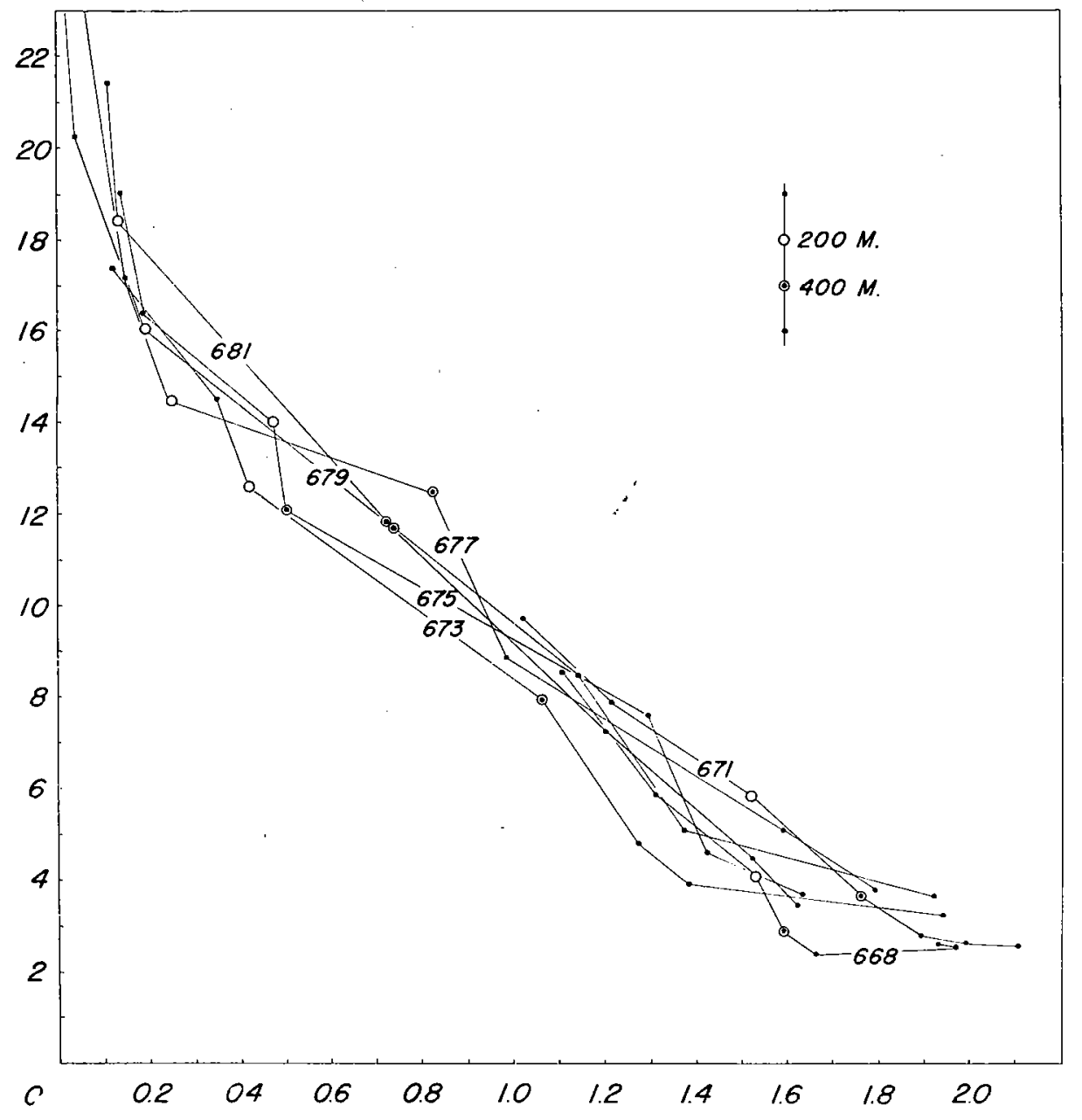

FIG. 10. Phosphate-temperature correlation in waters above $1, \infty 00$ meters depth in the temperate South Atlantic. "Discovery" stations between $46^{\circ}$ and $21^{\circ}$ south latitude. Ordinate; temperature $\left({ }^{\circ} \mathrm{C}\right)$ Abscissa; total phosphate (mg. atoms $\mathbf{P}$ per cubic meter). Observations at 200 and 400 meters denoted by characteristic symbols.

On the other hand, if the phosphate is derived principally from the decomposition of organisms which have sunk to the depths before undergoing decomposition, the phosphate-temperature relations observed in the surface will be destroyed, and in general the ratio of phosphate to temperature will be greater in deep waters than in subsurface waters of a given temperature. An examination of the data shows that in the Atlantic Ocean both these possibilities are realized, each in a different part of the section.

Figure Io shows the phosphate-temperature correla tion observed at the various "Discovery" stations in the South Atlantic distributed from about $46^{\circ}$ to $2 I^{\circ}$ south latitude. Within this belt the relation is quite uniform at all stations. Such scatter as exists is unsystematic and probably does not exceed the vagaries of the individual observations. At the more southern stations (668 and 67I) combinations of temperature and phosphate 


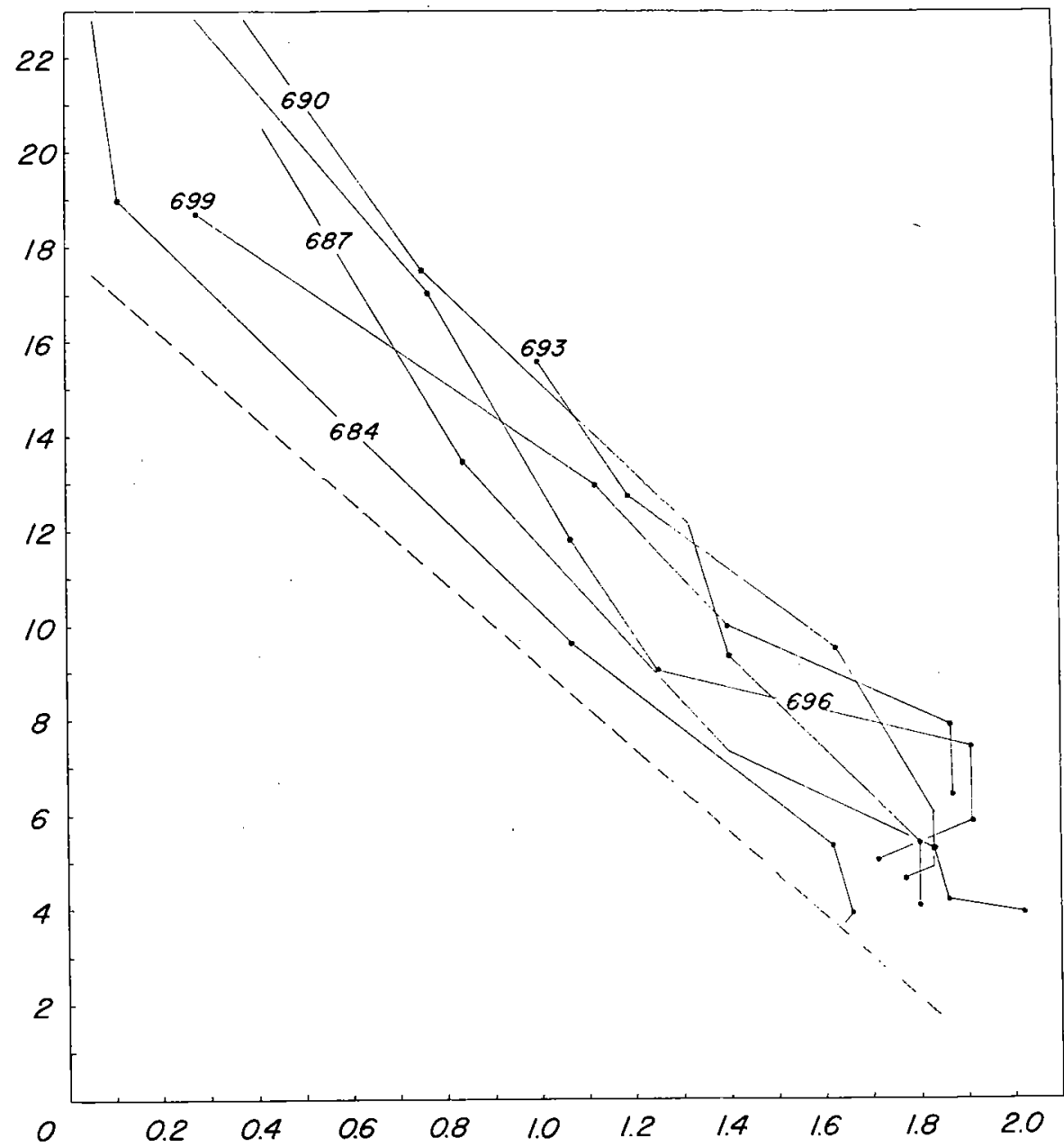

FIG. II. Phosphate-temperature correlation in waters above I,Ooo meters depth in the tropical South Atlantic. "Discovery" stations between $15^{\circ} \mathrm{S}$ and $8^{\circ} \mathrm{N}$ latitude. Ordinate; temperature $\left({ }^{\circ} \mathrm{C}\right)$. Abscissa; total phosphate (mg. atoms $\mathrm{P}$ per cubic meter). The broken line represents the correlation existing south of $21^{\circ} \mathrm{S}$ latitude.

concentration are observed at depths of 200 to 400 meters which are similar to those found at much greater depths in the more northern positions. Within this portion of the section the observations are compatible with the view that the phosphate-temperature correlations have been established by decomposition occurring within a few hundred meters of the surface, and that from these depths the water has spread to greater depths along isentropic surfaces, without serious modification of the phosphate concentration from the further decomposition of organisms. ${ }^{6}$

${ }^{6}$ An alternate explanation of the correlation might assume that the relation observed at any depth resulted from the vertical mixing at intermediate depths of sub-surface water of about $18^{\circ} \mathrm{C}$ and virtually free of phosphate with the water of $3^{\circ}$ or $4^{\circ} \mathrm{C}$ and of high phosphate content from the South Atlantic intermediate layer. However, this explanation also involves the idea that the phosphate content of these depths behaves as a conservative property, and is not significantly augmented by the sinking and decomposition of surface organisms. 


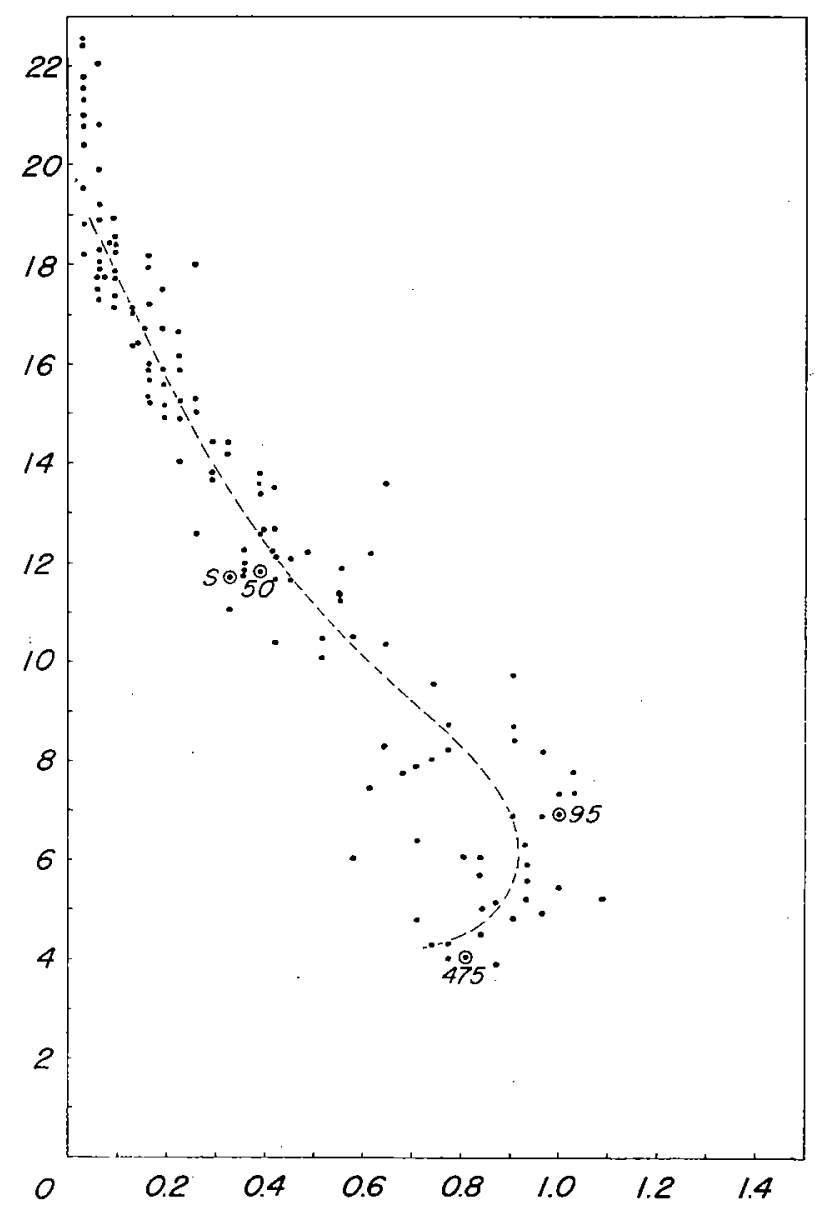

Fig. I2. Phosphate-temperature correlation in waters above $I, 000$ meters depth in the temperate North Atlantic. "Atlantis" stations between $25^{\circ} 53^{\prime} \mathrm{N}$ and $49^{\circ} 58^{\prime} \mathrm{N}$ and "Meteor" Station I $37\left(50^{\circ} 27^{\prime} \mathrm{N}\right)$. The measurements at the "Meteor" station are designated by circles enclosing dots. The adjacent numbers indicate their depth. Ordinate; temperature $\left({ }^{\circ} \mathrm{C}\right)$. Abscissa; total phosphate (mg. atoms $\mathrm{P}$ per cubic meter).

variation and the latitude or depth of observation. Apparently the measurements are not very precise or possibly there are small local variations in the phosphate content of neighboring bodies of water. Subject to this qualification the correlation of temperature and phosphate content may be interpreted, as in the case of the corresponding part of the South Atlantic section, as being due to isentropic movement of water through great distances without the occurrence of a serious modification of the relationship by the decomposition of plankton. It is noteworthy that the temperature-phosphate relation is quite different in these parts of the North and South Atlantic. The latter is characterized by much higher phosphate at a given temperature.

Throughout the part of the section occupied by the "Atlantis" stations there is very little variation in the depths at which particular temperature-phosphate relations are observed. At "Meteor" Station 137, however, combinations of temperature and phos-
At the stations of the "Disand $8^{\circ}$ north the uniform correlation of temperature and phosphate concentration observed farther south no longer obtains. Figure I I shows that at successive stations proceeding northward increasing phosphate concentrations occur at each tembeing reached at stations 690 and 693 , slightly north of the equator. The relation observed in these waters cannot have been established by the isentropic movement of subsurface waters from the more southern part of the section. It seems probable that the sinking of decomposing organisms from the surface layers has occurred in sufficient antities to effectively modify the inships set up in the water surface.

In the North Atlantic section similar conditions are repeated, though the data are somewhat less perature-phosphate correlation at all stations extending from $50^{\circ} 37^{\prime} \mathrm{N}$ ("Meteor" I37) to $25^{\circ} 53^{\prime} \mathrm{N}$ ("Atantis" II63). While there is much scatter in the individual points, an examination has shown that there is no systematic relation between this regular. Figure 12 shows the tem- 


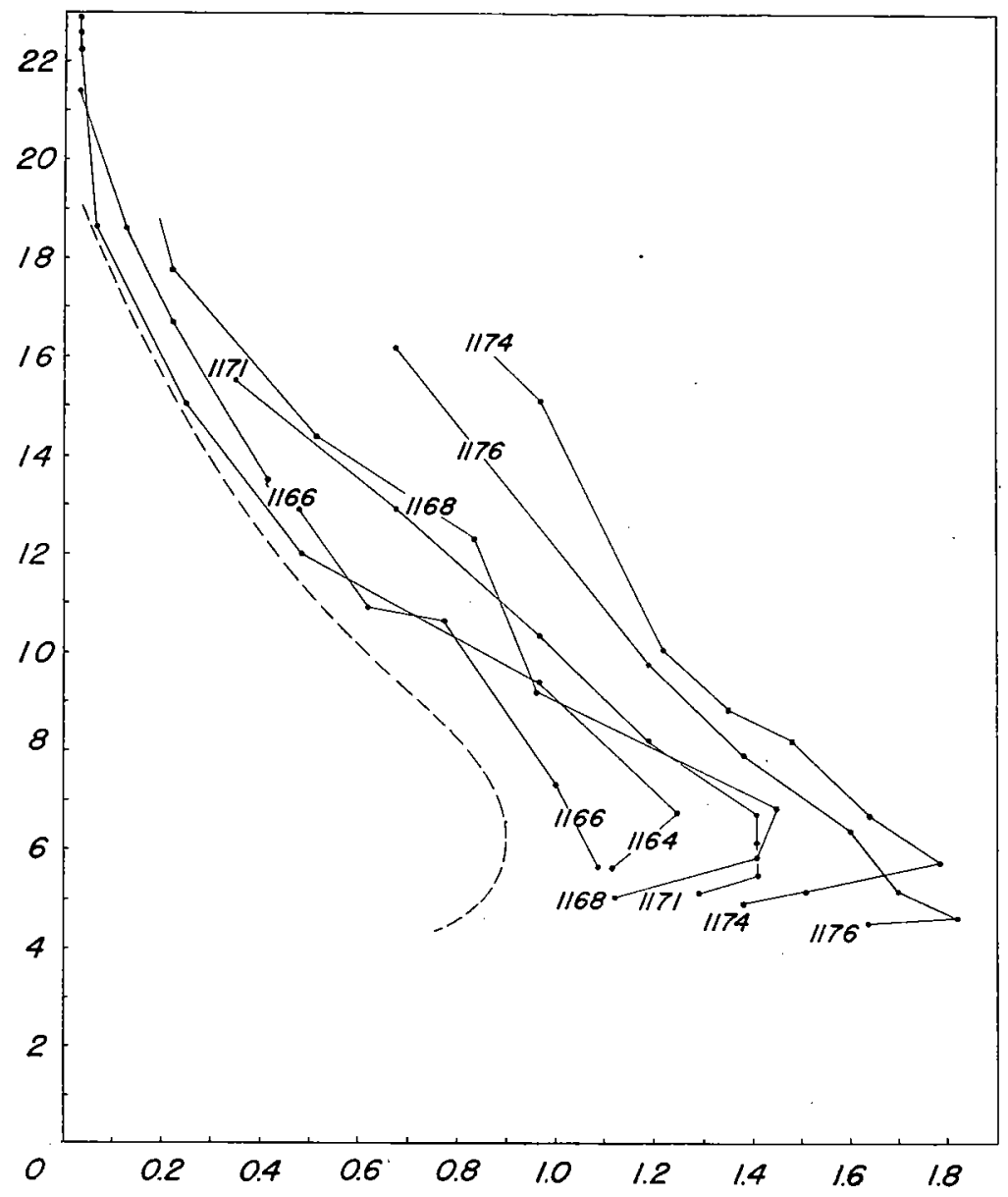

FIG. I3. Phosphate-temperature correlation in waters above 1,000 meters depth in the tropical North Atlantic. Selected "Atlantis" stations between $5^{\circ}$ I 6 'N (i i 76 ) and $24^{\circ} 06^{\prime} \mathrm{N}$ ( $\mathrm{Ir}_{4}$ ). Ordinate; temperature $\left({ }^{\circ} \mathrm{C}\right)$. Abscissa; total phosphate (mg. atoms $P$ per cubic meter). The broken line represents the correlation existing north of $25^{\circ} \mathrm{N}$ latitude.

phate concentration were observed within the upper hundred meters which correspond closely with those found at much greater depths for great distances to the south. At $50^{\circ} \mathrm{N}$ there existed water suitable to provide a source for the temperature-phosphate relationship found in remote parts of the North Atlantic basin.

South of $25^{\circ} \mathrm{N}$ the correlation of temperature and phosphate undergoes a progressive change as Figure 13 indicates. Increasing quantities of phosphate are found to coincide with a given water temperature, just as was observed in the South Atlantic section when the equatorial region is approached.

\section{DISCUSSION}

The present inquiry has aimed to determine to what extent it is possible to attribute the concentrations of phosphate, and similar derivatives of metabolic activity, observed within the depths of the ocean to the transport of water, in which decomposition has already taken place, from remote regions near the surface. 
It has been assumed that such transport is limited to flow or mixing along surfaces of constant potential density.

It has been found that:

r. The layer of maximum phosphate concentration occupying the temperate and tropical South Atlantic may be derived in part from isentropic movement of water from the subsurface of the antarctic convergence to considerable depths beneath the surface. This water carries phosphate which existed as such in the surface waters of high latitudes as well as phosphate derived from the oxidation of organic matter which originated in the antarctic.

2. The phosphate of the water of mid-depths, lying above the maximum, may also have acquired its characteristic phosphate content by isentropic movement from subsurface layers of higher latitudes.

3. Similar conditions obtain in the North Atlantic, save that the preformed phosphate present in the surface at the arctic convergence does not contribute to the phosphate maxima of the North Atlantic, but supplements considerably the phosphate of the deep water underlying the zone of maximum concentration. The phosphate maximum (and oxygen minimum) may be derived chiefly from the oxidation of organic matter within a few hundred meters of the surface in a region about $50^{\circ} \mathrm{N}$ latitude.

4. In the equatorial region additional phosphate is added to the water (and oxygen removed) by processes other than isen tropic movement. These additions may be attributed to the sinking of decomposing organisms from the surface of the tropical ocean to considerable depths.

If these possibilities are realized in nature, then one of the principal difficulties in accounting for the distribution of the nutrient maximum and oxygen minimum of the ocean is considerably lightened. It no longer becomes necessary to assume that sinking organisms arrive in quantity at the great depths at which these maxima and minima occur before undergoing decomposition. Decomposition may be thought to occur within a few hundred meters of the surface and its products distributed from there to much greater depths in remote regions by the isentropic movement of water.

It is only in the belt between $20^{\circ} \mathrm{S}$ and $25^{\circ} \mathrm{N}$ latitude that recourse must be made to the sinking of organisms to considerable depths. Here it is difficult to explain the observations without assuming that active decomposition is occurring down to depths of at least $600-800$ meters.

A second difficulty which is relieved by these suggestions concerns the relation between the intensity of the accumulation of nutrient salts (or the depletion of oxygen) in the oceanic basin and the density of population in the overlying surface waters, from which the decomposing material has been thought to be derived. The view here presented is that the condition of the deep water of the Atlantic Ocean in middle latitudes, which are known to be relatively barren, has not been determined by decomposition of organisms sinking from its surface, but rather by movement of water from regions far to the north or south. The deep waters derive their phosphate and lose their oxygen as the result of decomposition taking place either in the subsurface waters of the polar convergences, or under the surface of the equatorial current in tropical latitudes. These regions are both recognized to be characterized by unusually abundant fauna and flora and thus may be expected to yield large quantities of decomposing organic matter to the deeper waters which come within their influence. 


\section{SUMMARY}

I. A large part of the phosphate content and apparent oxygen utilization observed in the deeper layers of the North and South Atlantic may be attributed to characteristics acquired by the water when it was relatively near the sea surface in higher latitudes.

2. The distribution of surfaces of constant potential density permit the transport of water from the regions near the sea surface in which its characteristics are acquired to the depths at which maximum oxygen deficits and phosphate concentrations are observed.

3. In the tropical Atlantic, however, a large part of the observed phosphate concentration and oxygen deficit must be attributed to the decomposition of organisms which have sunk from the sea surface to depths as.great as $600-800$ meters.

4. The principal sources of the products of organic decomposition observed in the deep waters of the Atlantic appear to be the unusually abundant flora and fauna found in the subsurface waters of the arctic and antarctic convergences and of the equatorial current.

Clowes, A. J.

\section{REFERENCES}

I938. Phosphate and silicate in the Southern Ocean. Discovery Reports, Vol. XIX, pp. $3^{-120 .}$

Conseil permanent international pour l'exploration de la mer.

I933. Bulletin Hydrographique pour l'annee 1932.

1936. Bulletin Hydrographique pour l'annee 1935 .

CoOper, L. H. N.

I937. On the ratio of nitrogen to phosphorus in the sea. Journ. Mar. Biol. Assoc., Vol. XXII, pp. I77-I 82 .

Dietrich, G.

I937. "Die dynamische Bezugsfläche," ein Gegenwartsproblem der dynamischen Ozeanographie. Ann. d. Hydr. u. Mar. Met., Bd. 65, pp. 506-519.

Discovery Reports

I932. Station list I929-3I. Vol. IV, pp. I-232.

Fleming, R. H.

I941. Composition of plankton and units for reporting populations and production. Proc. Sixth Pacific Sci. Congress, pp. 535-540.

IsELIN, C. O'D.

1939. The influence of vertical and lateral turbulence on the characteristics of the waters at mid-depths. Amer. Geophysical Union, Transactions, pp. 4I4-4I 7 .

JACOBSEN, J. P.

I9I6. Contribution to the hydrography of the Atlantic. Medd. Komm. Havunders, Ser. Hydrografi, Bd. II, No. 5, 23 pp.

Mon'tgomeri, R. B.

1938. Circulation in upper layers of southern North Atlantic deduced with use of isentropic analyses. Papers in Physical Oceanography and Meteorology, Vol. VI, No. 2, 55 pp.

1940. The present evidence on the importance of lateral mixing processes in the ocean. Bull. Amer. Meteorological Soc., Vol. 21, pp. 87-94. 
ReDField, A. C.

1934. On the proportions of organic derivatives in sea water and their relation to the composition of plankton. James Johnstone Memorial Volume, Liverpool, pp. $176-192$.

Seiwell, H. R.

1937. The minimum oxygen concentration in the western basin of the North Atlantic. Papers in Physical Oceanography and Meteorology, Vol. V, No. 3, 24 pp.

Spilhaus, A. F.

I94I. Fine structure of the edge of the gulf stream. Trans. American Geophysical Union, pp. $478-484$.

Sverdrup, H. V.

1938. On the explanation of the oxygen minima and maxima in the oceans. Journ. du Conseil, Vol. XIII, pp. 163-172.

Wattenberg, $\mathrm{H}$.

1929. Die Durchlüftung des Atlantischen Ozeans. Journ. du Conseil, Vol. IV, pp. 68-79.

1937. Die chemischen Arbeiten auf der "Meteor," Fahrt Februar bis Mai, I937. Ann. d. Hydr. u. Mar. Met., Bd. 65, Meteor Beiheft, pp. 17-22.

1938. Die Verteilung des Sauerstoffs und des Phosphats im Atlantischen Ozean. Wiss. Ergeb. der Deutschen Atlant. Exped. "Meteor," I925-I927. Bd. IX, Teil II, Wüst, G. Lief. I., pp. I-132.

1935. Schichtung und Zirkulation des Atlantischen Ozeans. Die Stratosphäre. Wiss. Ergeb. der Deutschen Atlant. Exped. "Meteor," I925-1927. Bd. VI, Teil I, pp. 109-288. 